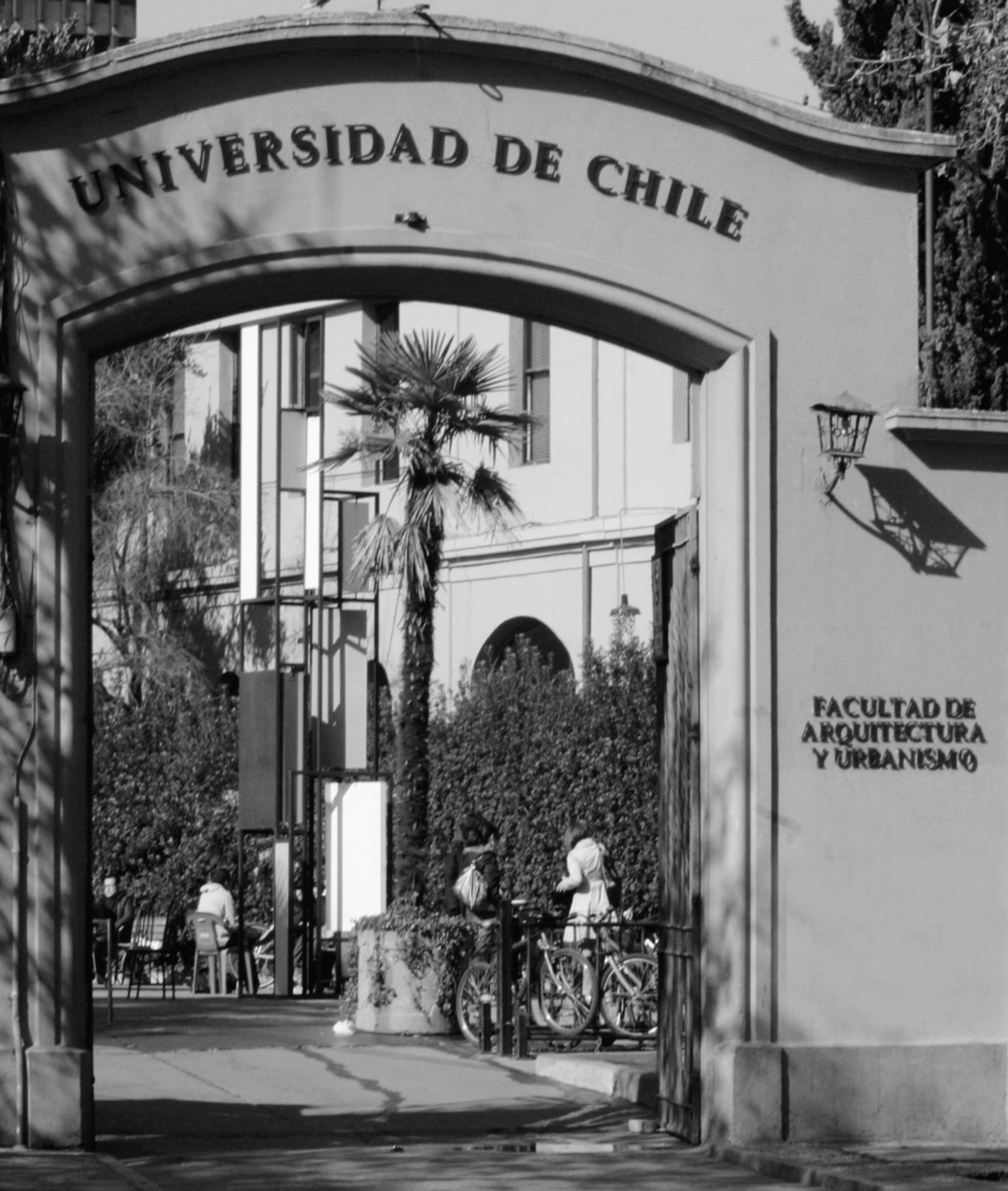




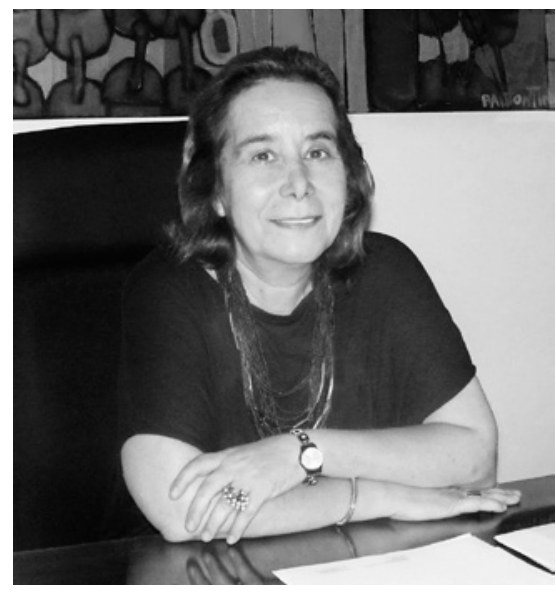

MARCELA PIZZI KIRSCHBAUM

Decana

Facultad de Arquitectura y Urbanismo Universidad de Chile

\section{Palabras de la Decana}

as publicaciones periódicas de naturaleza científica, como vehículo de divulgación del _conocimiento, cobran creciente relevancia en un contexto académico hiperconectado. Las fronteras ya no son tales si se trata del conocimiento; las revistas académicas constituyen, en efecto, un vehículo imprescindible para transmitir y compartir resultados de investigación y de otros productos de interés científico y académico, enriqueciendo consecuentemente, el debate disciplinar. En dicho marco, nuestra Revista de ARquitectura de la Facultad de Arquitectura y Urbanismo de la Universidad de Chile, es expresión de la voluntad de acoger contenidos de excelencia académica, ofreciendo espacios a una diversidad de enfoques y a distintas aproximaciones que den razón a la multidimensionalidad de la arquitectura y sus manifestaciones afines.

Los soportes electrónicos, por su lado, facilitan la necesidad de compartir el conocimiento de manera eficaz, amplia y dinámica profundizando la democratización en el acceso al saber. En este escenario, la ReVISTA DE ARQUITECTURA ha orientado últimamente sus esfuerzos en consolidar su espacio en la plataforma que ofrece el Portal de Revistas Académicas de la Universidad de Chile ${ }^{[1]}$, planteándose un nuevo impulso para ampliar la cobertura de la Revista a nivel nacional e iberoamericano, y con ello, contribuir al fortalecimiento en las relaciones académicas entre instituciones, investigadores, profesores y estudiantes.

Reconociendo la importancia de los soportes electrónicos, se valora paralelamente, la versión impresa de la REVISTA DE ARQUITECTURA, como objeto representativo de una tradición de larga data y como registro tangible de un patrimonio en permanente construcción. Tal como el libro, la revista en papel cumple un rol complementario a sus versiones digitales. De tiraje limitado y sujeto a los requerimientos de su financiación, la revista impresa es ciertamente un soporte de menor alcance e impacto; no obstante, representa para muchos, la evidencia de su permanencia en el tiempo, como también una carta de presentación de una institución.

El presente número explora la temática de la teoría en el proyecto a través de diversos artículos reflexivos sobre la interacción entre la teoría y la práctica en arquitectura, materia que cobra especial relevancia para nuestra disciplina en los tiempos vertiginosos que vivimos. 